\title{
Evaluation of Diesel Engine Performance and Exhaust Emission Characteristics using Waste Cooking Oil
}

\author{
NUR ATIQAH Ramlan ${ }^{1, a}$, ABDUL ADAM Abdullah", ${ }^{1,}$, \\ MOHD HERZWAN Hamzah ${ }^{1, c}$, NUR FAUZIAH Jaharudin ${ }^{1, d}$ \\ and RIZALMAN Mamat ${ }^{1, \mathrm{e}}$
}

\author{
${ }^{1}$ Faculty of Mechanical Engineering, Universiti Malaysia Pahang, 26600 Pekan, Pahang, Malaysia. \\ aatiqahramlan3@gmail.com, badam@ump.edu.my, cherzwan@gmail.com, dfauziahjs@gmail.com, \\ rizalman@ump.edu.my
}

Keywords: Alternative fuel, biodiesel, engine performance, exhaust emission, waste cooking oil.

\begin{abstract}
The depletion of fossil fuels as well as the rises of greenhouse gases had caused most government worldwide to follow the international energy policies for the use of biodiesel. One of the economical sources for biodiesel production is waste cooking oil. The use of waste cooking oil is more sustainable if they can perform similarly to conventional diesel fuel. This paper deals with the experimental study carried out to evaluate the engine performance and exhaust emission of diesel engine operated by biodiesel from waste cooking oil at various engine speed. The biodiesel used are known as B5, which contains of 5\% of waste cooking oil and $95 \%$ of diesel fuel. The other one is B20, which contains of $20 \%$ of waste cooking oil plus $80 \%$ of diesel. Diesel was used as a comparison purposes. The results show that power and torque for B5 give the closest trend to diesel. In terms of heat release, diesel still dominates the highest value compared to B5 and B20. For exhaust emission, $\mathrm{B} 5$ and $\mathrm{B} 20$ showed improvement in the reduction of $\mathrm{NO}_{\mathrm{x}}$ and $\mathrm{PM}$.
\end{abstract}

\section{Introduction}

The extensive usage of diesel engines has led to an increase in demand for diesel fuel, thus causing the decrease of petroleum fuel stocks. Moreover, the consumption of diesel fuel also gives negative effect to the environment by the rises of greenhouse gases. At this point, attention has been given towards the production of biodiesel as an alternative fuel. For example in Malaysia, the government had already mandated the use of B5 nationwide. The transesterification process in biodiesel production ensures that glycerine, catalyst and alcohol are removed from the oil in order to meet the regulation of biodiesel standard, ASTM 6751. One of the reasonable sources of biodiesel is waste cooking oil since it is easy to get and the cost for biodiesel production is 2 to 3 times cheaper than vegetable oils [1].

Many researchers have proved that biodiesel from waste cooking oil can improve exhaust emissions by reducing carbon monoxide, hydrocarbon and particulate matter [2-4]. However, the high viscosity of waste cooking oil still becomes a major problems since it can cause many engine problems such as poor atomization and carbon deposition $[5,6]$. In order to overcome these problems, most researchers used a small percentage of waste cooking oil to be blended with diesel fuel and tested for engine compatibility.

In this present study, two types of biodiesel which produced from waste cooking oil were used to evaluate the diesel engine performance and exhaust emissions. These test fuels were compared with ordinary diesel fuel. The engine performance parameters are including indicated power, torque and heat release which based on the experimental data collected from the test engine. The emission parameters such as $\mathrm{CO}, \mathrm{CO}_{2}, \mathrm{NO}_{\mathrm{x}}$ and $\mathrm{PM}$ were measured during the engine performance test.

\section{Materials and Methods}

In this study, three test fuels have been used for engine testing, namely diesel, B5 and B20. B5 and B20 were based on biodiesel from waste cooking oil. B5 comprises of 5\% waste cooking oil 
and $95 \%$ diesel fuel, and B20 contains of $20 \%$ waste cooking oil and $80 \%$ diesel fuel.The measurement of the fuel properties was conducted in order to ensure that all biodiesel is complied with ASTM biodiesel standard. The chemical properties of each fuel are shown in Table 1.

Table 1: Chemical properties of test fuels

\begin{tabular}{lcccc}
\hline Parameter & ASTM D6751 & Diesel & B5 & B20 \\
\hline Density $\left(\mathrm{g} / \mathrm{cm}^{3}\right)$ & 0.88 & 0.843 & 0.844 & 0.851 \\
Cetane Number & $>46$ & 46.6 & 46.9 & 48.9 \\
Calorific Value $(\mathrm{MJ} / \mathrm{kg})$ & N/A & 42.32 & 42.08 & 38.67 \\
Kinematic Viscosity at $40^{\circ} \mathrm{C}\left(\mathrm{mm}^{2} / \mathrm{s}\right)$ & $1.9-6.0$ & 3.718 & 3.754 & 3.829 \\
Cloud Point $\left({ }^{\circ} \mathrm{C}\right)$ & N/A & -3 & 0 & 0 \\
Pour Point $\left({ }^{\circ} \mathrm{C}\right)$ & N/A & -10 & -9 & -8 \\
\hline
\end{tabular}

This experimental study was done according to the SAE J1349 standard. A YANMAR TF120 single cylinder, four strokes, naturally aspirated with water cooled diesel engine was used as the test engine. The specifications of the test engine are listed in Table 2. Fig. 1 represents the schematic diagram of the experimental setup. The fuel control unit was placed next to the engine fuel pump and it was separated in two different tanks, called diesel fuel tank and alternative fuel tank. For the dynamometer system, a gear pump was used in order to apply load to the test engine. The data from the engine testing were collected and processed using data acquisition system by TFX Engineering. In addition, the exhaust emission sampling was divided in two parts, which are exhaust gas analyser and filter for particulate matter sampling purpose. Parameters that produced and analysed by this experimental study were engine power, engine torque, heat release and exhaust emission. The engine testing was repeated for three times, and the average value was taken.

Table 2: Engine specifications

\begin{tabular}{ll}
\hline Description & Specification \\
\hline Engine model & YANMAR TF120 \\
Number of cylinders & 1 \\
Bore x Stroke (mm) & $92 \times 96$ \\
Displacement (L) & 0.638 \\
Compression ratio & 17.7 \\
Continuous output (HP) & $10.5 \mathrm{HP}$ at 2400 RPM \\
Rated output (HP) & $12 \mathrm{HP}$ at 2400 RPM \\
\hline
\end{tabular}

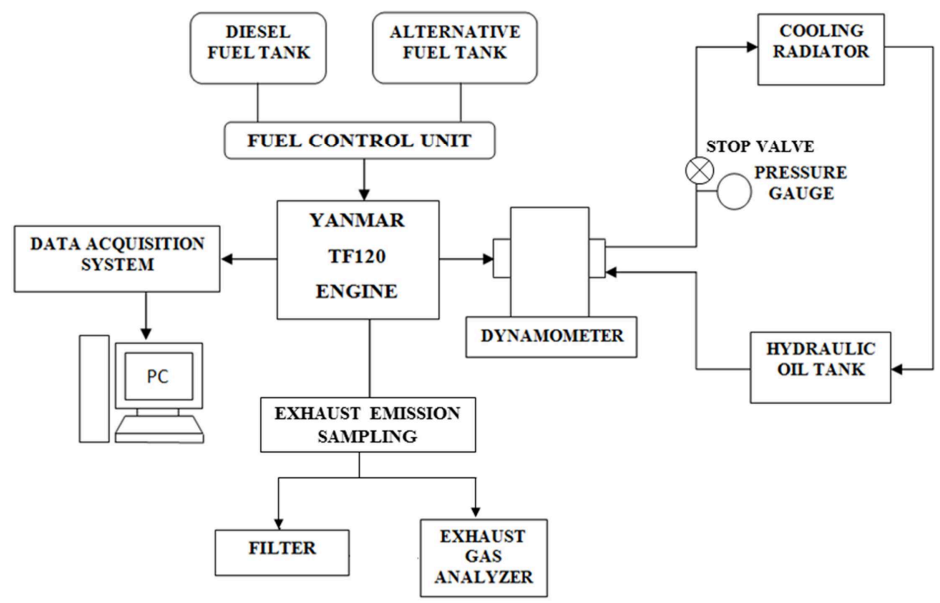

Fig. 1: Schematic diagram of the experimental setup 


\section{Result and Analysis}

A comparison of the engine power and torque produced by all test fuels is represents in Fig. 2(a) and (b). As seen in the figure, power and torque for all test fuels shows a linear increase as the speed increases. Thus, all test fuels were marked the maximum power and torque value at engine speed of $2400 \mathrm{rpm}$. With the increase in biodiesel blends ratio, it can be seen that the power and torque produced is lower compared to diesel, which is in agreement with the literature [7-9]. This is obviously because of the chemical properties of biodiesel, especially the lower calorific value of B5 and B20 as compared with diesel.

The results of heat release produced by all test fuels at lowest and highest engine speed are shown in Fig. 3(a) and (b). This figure shows that B5 and B20 have identical combustion stages similar to diesel. However, it can be seen that the heat release increase as the engine speed increase. The location of peak of heat release also delayed and shifted away from TDC with the increment of the engine speed. Moreover, compared to the other test fuels, diesel marked the highest heat release at $1200 \mathrm{rpm}$ and $2400 \mathrm{rpm}$ engine speeds, with the value of $31.9 \mathrm{~J} /$ degree and $37.9 \mathrm{~J} /$ degree respectively. The lower heat release by B5 and B20 is due to their lower volatility of $0.57 \%$ and $8.62 \%$ respectively as compared to diesel.

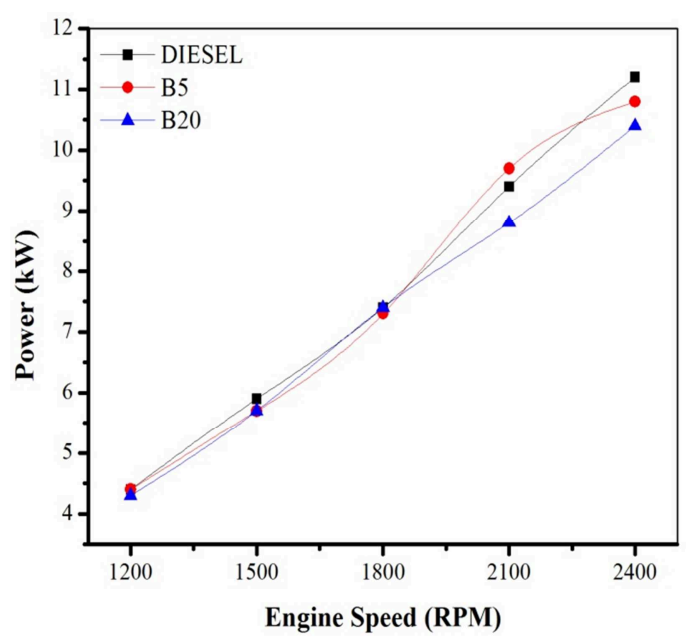

(a)

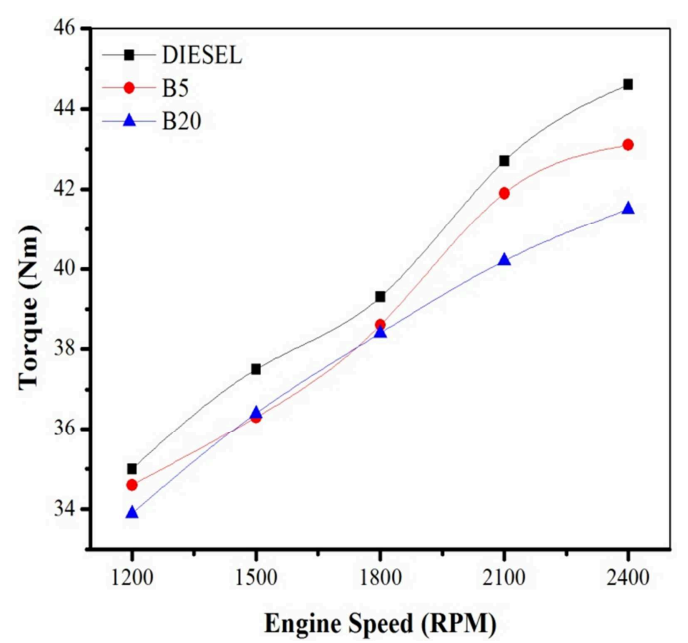

(b)

Fig. 2: (a) Power values for all test fuels, (b) Torque values for all test fuels

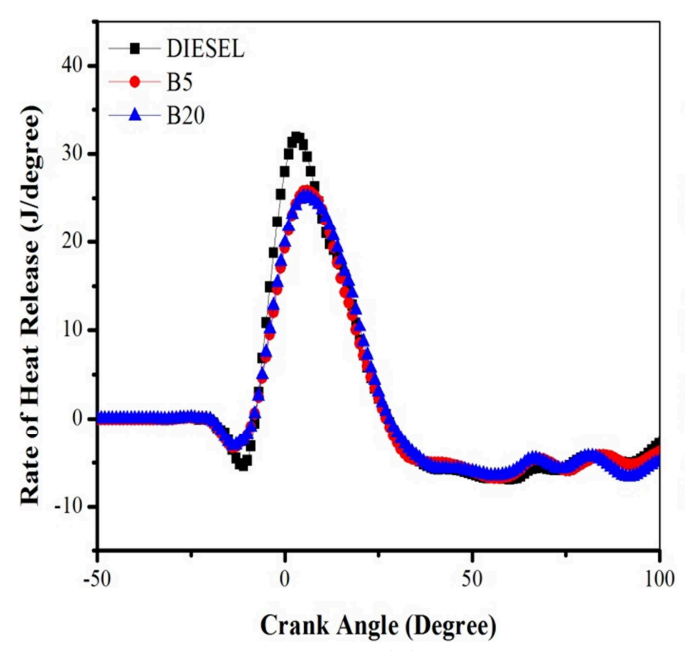

(a)

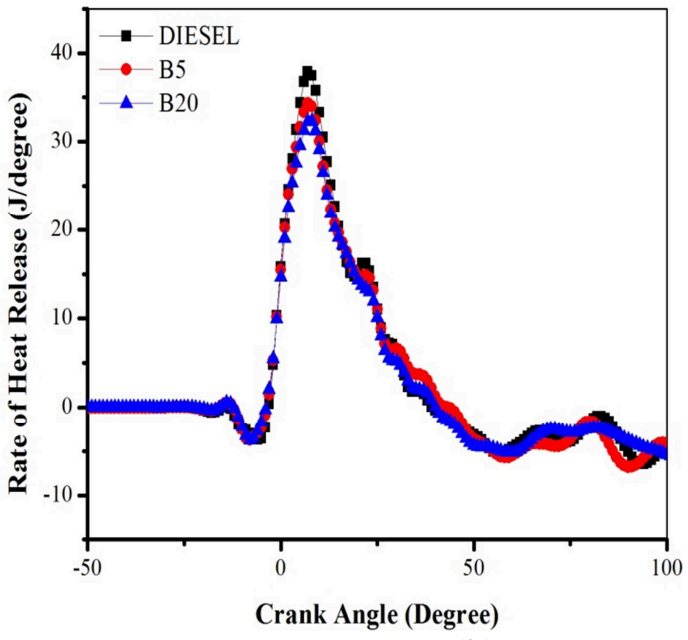

(b)

Fig. 3: (a) Heat release rate at $1200 \mathrm{rpm}$, (b) Heat release rate at $2400 \mathrm{rpm}$

The comparison of gases emission and particulate matter distribution for all test fuels at various engine speed is shown in Fig. 4(a), (b), (c) and (d). Considering the NOx emission as seen in Fig. 
4(a), the usage of B5 and B20 instead of diesel, resulted in small different of $0.2 \%$ to $5.7 \%$ as the engine speed increase. However, at lowest engine speed of $1200 \mathrm{rpm}$, NOx produced by B5 and B20 are higher than diesel. This phenomenon might have happened because of structural oxygen content of biodiesel, that improved the oxidation of nitrogen and raised the combustion temperature [10]. The $\mathrm{CO}$ emission results are shown in Fig. 4(b). The CO emissions for B20 had a significant increased from about $42 \%$ to $83 \%$ when engine speed increase as compared to diesel. B5 also produced higher $\mathrm{CO}$ than diesel, however at $1800 \mathrm{rpm}$, the emission is similar with diesel. The increase of $\mathrm{CO}$ emission by biodiesel blends might be due to the high viscosity and poor spray characteristics of biodiesel, thus leading to incomplete combustion. For $\mathrm{CO}_{2}$ emissions as can be seen in Fig. 4(c), B5 and B20 released higher $\mathrm{CO}_{2}$ as compared to diesel. This is obviously because of average carbon content per energy of biodiesel which is higher than diesel. The other significant emissions from diesel engines are PM emission which can contribute to serious human health effect and environment pollution. The PM concentration of all test fuels can be seen in Fig. 4(d). Overall, as the engine speed increase, PM concentration is also increase. B5 seems to have similar results with diesel with a small variance. However, there is a significant reduction of $20 \%$ by B20 as compared to diesel at $2400 \mathrm{rpm}$ engine speed. This is due to the high oxygen content of B20 which caused a reduction in soot formation and thus enhanced soot oxidation [11].

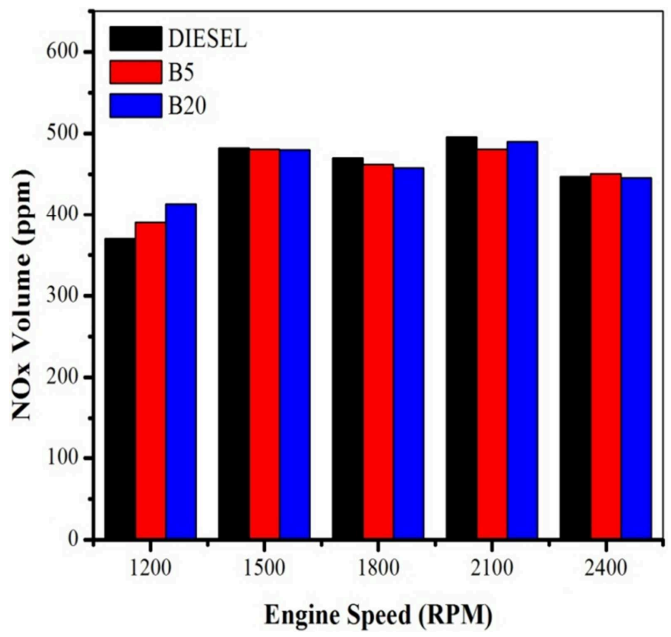

(a)

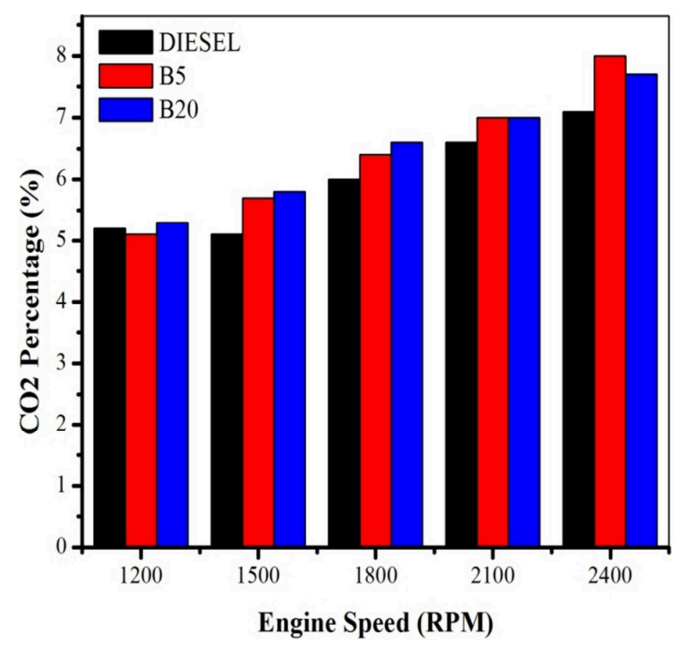

(c)

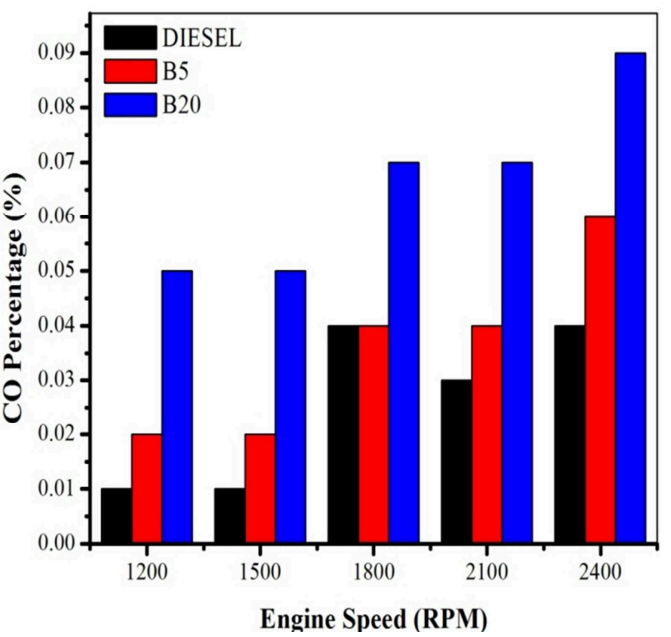

(b)

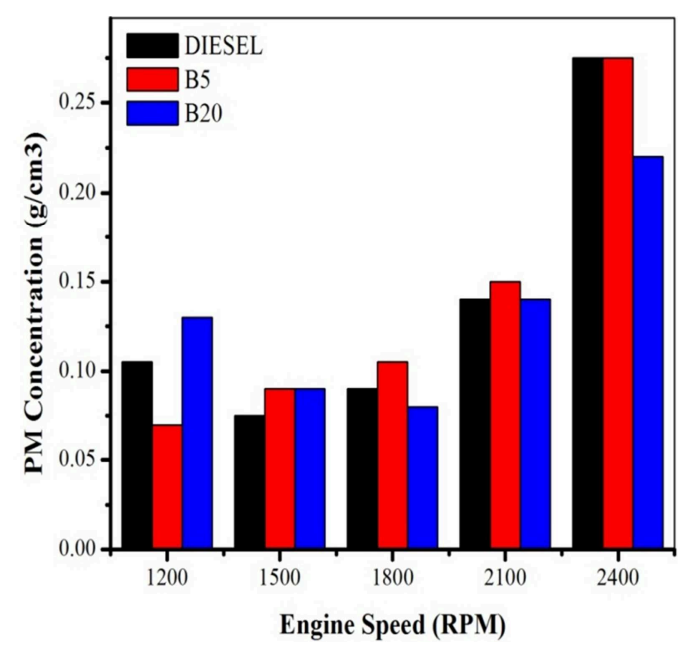

(d)

Fig. 4: (a) $\mathrm{NO}_{\mathrm{x}}$ emissions at various engine speeds, (b) $\mathrm{CO}$ emissions at various engine speeds, (c) $\mathrm{CO}_{2}$ emissions at various engine speeds, (d) $\mathrm{PM}$ emissions at various engine speeds 


\section{Conclusion}

The engine performance and exhaust emission characteristics of diesel and biodiesel blends derived from waste cooking oil (B5 and B20) were compared. The experimental result showed that the power and torque characteristics for biodiesel blends were almost similar with diesel. For heat release, both B5 and B20 indicated a lower heat release as compared to diesel. Moreover, B5 also showed a close resemblance with diesel in terms of exhaust emissions. These results indicate that biodiesel blends can be used as a diesel substitute without any modification on the engine.

\section{References}

[1] Phan, A.N. and T.M. Phan, Biodiesel production from waste cooking oils. Fuel. 87 (2008) 3490-3496.

[2] Lin, Y.-C., K.-H. Hsu, and C.-B. Chen, Experimental investigation of the performance and emissions of a heavy-duty diesel engine fueled with waste cooking oil biodiesel/ultra-low sulfur diesel blends. Energy. 36 (2011) 241-248.

[3] Muralidharan, K. and D. Vasudevan, Performance, emission and combustion characteristics of a variable compression ratio engine using methyl esters of waste cooking oil and diesel blends. Applied Energy 88 (2011) 3959-3968.

[4] Abu-Jrai, A., et al., Combustion characteristics and engine emissions of a diesel engine fueled with diesel and treated waste cooking oil blends. Chemical Engineering Journal 172 (2011) 129136.

[5] Mamat, R., et al., Characteristics of biodiesel fuel derived from palm oil. Journal of Biobased Materials and Bioenergy. 6 (2012) 1-4.

[6] Adam, A., et al., Analysis of Straight Vegetable Oil (SVO) Spray Characteristics and Droplets Distribution By Using Nano-Spark Shadowgraph Photography Technique, in The 3rd International Renewable Energy Congress. (2011).

[7] Orkun, O., et al., Effects of soybean biodiesel on a DI diesel engine performance, emission and combustion characteristics. Fuel. 115 (2014) 875-883.

[8] Dhar, A. and A.K. Agarwal, Performance, emissions and combustion characteristics of Karanja biodiesel in a transportation engine. Fuel. 119 (2014) 70-80.

[9] Lapuerta, M., et al., Effect of the alcohol type used in the production of waste cooking oil biodiesel on diesel performance and emissions. Fuel. 87 (2008) 3161-3169.

[10] Mofijur, M., et al., Effect of biodiesel from various feedstocks on combustion characteristics, engine durability and materials compatibility: A review. Renewable and Sustainable Energy Reviews. 28 (2013) 441-455.

[11] Enweremadu, C.C. and H.L. Rutto, Combustion, emission and engine performance characteristics of used cooking oil biodiesel-A review. Renewable and Sustainable Energy Reviews. 14 (2010) 2863-2873. 